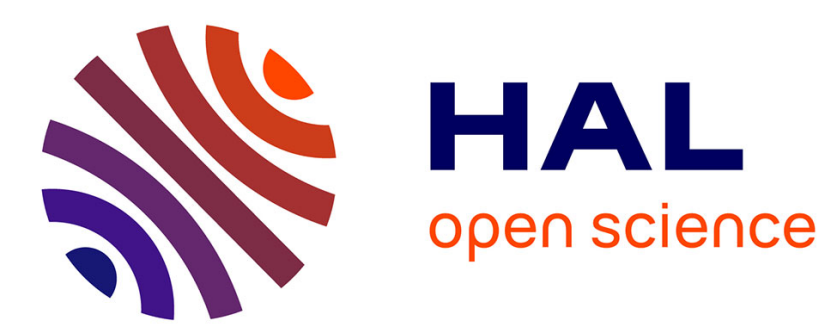

\title{
Defense for Covert Administrative Techniques for Neutralizing American Highly Qualified Personnel
}

\author{
Joshua M Pearce
}

\section{To cite this version:}

Joshua M Pearce. Defense for Covert Administrative Techniques for Neutralizing American Highly Qualified Personnel. American Intelligence Journal, 2016, 33, pp.126 - 136. hal-02111408

\section{HAL Id: hal-02111408 \\ https://hal.science/hal-02111408}

Submitted on 26 Apr 2019

HAL is a multi-disciplinary open access archive for the deposit and dissemination of scientific research documents, whether they are published or not. The documents may come from teaching and research institutions in France or abroad, or from public or private research centers.
L'archive ouverte pluridisciplinaire HAL, est destinée au dépôt et à la diffusion de documents scientifiques de niveau recherche, publiés ou non, émanant des établissements d'enseignement et de recherche français ou étrangers, des laboratoires publics ou privés. 
Preprint: Joshua M. Pearce. Defense for Covert Administrative Techniques for Neutralizing American Highly Qualified Personnel. American Intelligence Journal. Vol. 33, No. 2, pp. 126-136, 2016 (in print 2017).

\title{
Defense for Covert Administrative Techniques for Neutralizing American Highly Qualified Personnel
}

\author{
Joshua M. Pearce
}

\begin{abstract}
Ph.D. scientists and engineers are highly qualified personnel (HQP) that improve U.S. economic efficiency and generate new products including weapons of interest to the intelligence community. HQP represent a small fraction of the population, which make them favorable targets to compromise. This study analyzes how to defend against a novel approach of covert infiltration that uses administrative techniques to neutralize HQP without recruiting them directly. The approach follows five hierarchical strategies to replace the innovation cycle with administrative time expenditures. This approach is critically analyzed to further national security goals by providing intelligence service guidelines for defensive measures needed against this new weapon.
\end{abstract}

Keywords: counter intelligence; covert action; highly qualified personnel; scientists; neutralization; national security

\section{Introduction}

Highly qualified personnel (HQP) have historically only garnered the interest of the intelligence community when their skills were directly applicable to weapons systems (e.g. nuclear weapons scientists). ${ }^{1}$ However, advanced training in science and engineering is an integral part of university research in order to foster innovation. ${ }^{2}$ This engineering and science training contributes to the availability of a highly skilled labor force, capable of thinking critically and creating and applying knowledge for the benefit of the nation (e.g. by the creation of new technologies and industries). ${ }^{3}$ Cross national analysis shows that the size of a nation's scientific labor force and training system has a clear positive effect on economic development in a given country, which supports conventional theories that state training of HQP are valuable form of human capital that improves labor force efficiency and productivity. ${ }^{4}$ In addition, HQP in science and engineering contribute to national competitiveness and productivity because their output (research) produces knowledge, innovation and technical applications that improve economic efficiency and generates new products including weapons that are of interest to intelligence communities. ${ }^{5}$ With the average IQ of a Ph.D. in the top $5 \%$ of the population ${ }^{6}$ and the time needed to obtain a Ph.D. normally over 10 years past high school, the nation has made a substantial investment in their education and generally seeks to have the highest return based on efficient use of HQP research time to generate new knowledge. ${ }^{7}$ HQP trained in science and engineering and particularly those that train others (e.g. university professors) are ideally positioned to think creatively, capitalize upon new ideas and technologies developed in a target country and elsewhere in the world in any field. ${ }^{8}$ These HQP, however, represent a very small number of individuals. There are less than 1.5 million professors in the U.S., which represents less than $0.5 \%$ of the population ${ }^{9}$ as only $5-10 \%$ of Ph.D.s in engineering and science, respectively generally become faculty. ${ }^{10}$ With such a small number of individual HQP being responsible for the majority of technical innovation in a country like the U.S., competing intelligence organizations have several choices based on historical actions to neutralize them. These options historically included both assassination ${ }^{11}$ and some form of infiltration or recruitment through bribery or extortion. ${ }^{12}$ Assassination, whose moral complexities ${ }^{13}$ are left for discussion elsewhere, may be functionally practical for a few scientists in a specific sub-field of interest (e.g. biological weapons ${ }^{14}$ ). However, it is impractical for the larger scientific and engineering community of the U.S. or other nation without transparent aggression being detected. Similarly, although it is possible to imagine foreign intelligence services infiltrating and recruiting all of academia in a specific country, it would be clearly time consuming, difficult to implement and prohibitively expensive. These reasons explain why there is no reports in the literature of a mass-scale attack on a country's HQP.

This article analyzes a new potential approach of covert infiltration to enable administrative techniques to neutralize HQP in a country without recruiting HQP directly. Scientist and engineering faculty are a finite resources and have finite time. In the U.S. an average academic works about 60 hours per week. ${ }^{15}$ Roughly $2 / 3$ rds of that is for teaching ${ }^{15}$, including course preparation and advising. About a fifth of the work time for an average HQP working as a professor is spent on both research and administrative tasks. ${ }^{15}$ So to cripple the American innovation cycle an intelligence service infiltrating administrative ranks would only need to shift $\sim 20 \%$ percent of HQP time to administration, which represents 12 hours a week per HQP. This study outlines five hierarchical strategies that could be used by foreign intelligence services to increase administrative time expenditures for target HQP in the areas of grant writing, purchasing, reporting, outreach, budget accounting, safety, computer security, and sensitivity training. 
Preprint: Joshua M. Pearce. Defense for Covert Administrative Techniques for Neutralizing American Highly Qualified Personnel. American Intelligence Journal. Vol. 33, No. 2, pp. 126-136, 2016 (in print 2017).

The goal of these strategies is to utilize so much of the working time of HQP on non-productive labor that they are not able to produce any innovation of value. In addition, more advanced techniques for maximizing overhead parasitism will be explained. These approaches will be critically analyzed and discussed to provide intelligence service guidelines for defense against this new weapon to further goals of national security in the U.S.

\section{Methods}

The methods used to transition HQP time to non-productive administrative activities are organized in five hierarchies of 1) repetition, 2) internal oversight, 3) external oversight, 4) scope and 5) intrusion. All of these hierarchies can be integrated into existing administration practices by intelligence personnel directly or through recruited administrators (referred to for the remainder of this paper as administrative assets) whether by direct infiltration of university systems or the government of the U.S. Then detection and defensive measures will be outlined for each activity.

\section{Hierarchy in Repetition}

Hierarchy in repetition represents a method of taking an administrative task, which may be necessary or beneficial, and increasing the time burden by increasing the cycle repetition for the HQP to counteract that benefit by reducing HQP time on productive tasks. This is illustrated in Figure 1 and can be immediately implemented for any existing administrative function by taking the existing time cycle and altering policy for the next level up the pyramid shown in Figure 1. There is also the potential necessity for further time degradations. So for example, if faculty must already complete a self-study annually on their progress in research, teaching and service, a compromised administrative asset can recommend that such a self- study take place bi-or tri-annually after each semester. Once this policy is in place, and demonstrated to be successful the self-study can be mandated monthly and so forth. At each stage, to increase the time investment it is only necessary to show a benefit from the existing practice.

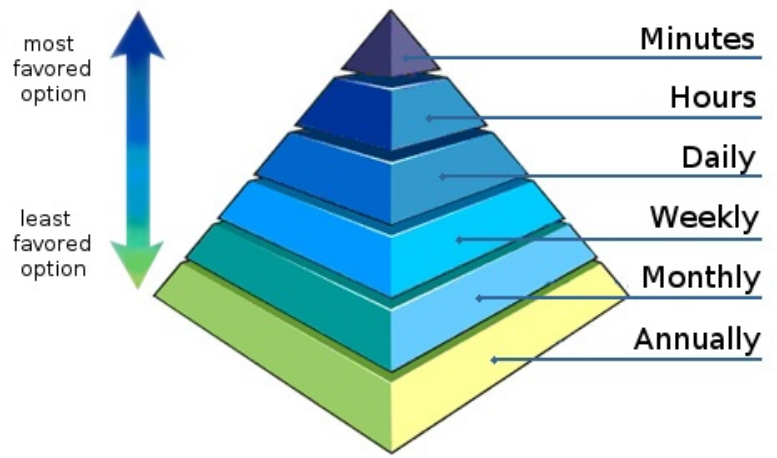

Figure 1. Hierarchy in Repetition from Enemy Intelligence Perspective

\section{Hierarchy in Oversight}

In order to both foster excellence and protect against internal maleficence, academic organizations institute some form of oversight. The goal of this hierarchy (shown in Figure 2) is to increase the time investment necessary for HQP to comply with internal oversight. If this begins, for example, with an annual self-study of normal academic functions the time investment can be extended substantially by mandating a peer-review of these documents (e.g. by requiring three faculty HQP to read each self-study). Any other type of normal administrative task can be multiplied in this way. So for example instead of a single letter of reference from an HQP being needed for graduate school, three, or five or ten can be required. The HQP time investment can be extended further by increasing the number of peerreviewers (e.g. 5, 10, or the entire department), but also by demanding further reporting higher up the academic hierarchy itself. As some administrators are themselves some of the most valuable HQP, it is imperative from a foreign enemy's perspective that any contributions they make to research are eliminated. This can be done in part by requiring a summary document for each one in order to go up to the next level in the hierarchy. So for an example, a department head would need to read the reports from peer review and make a new summary report for the dean, and so forth.

To foster compliance, administrative assets can be instructed by foreign handlers to use potential crisis examples from either their own institution or other institutions. For example, if University A was implicated in 
Preprint: Joshua M. Pearce. Defense for Covert Administrative Techniques for Neutralizing American Highly Qualified Personnel. American Intelligence Journal. Vol. 33, No. 2, pp. 126-136, 2016 (in print 2017).

academic plagiarism, University B can use the negative publicity to push through a crisis policy that demands that no plagiarism of any kind will be tolerated on campus to ensure academic excellence. Most academic HQP will agree with this sentiment and would be expected to vote for such a policy. Then University B can implement the policy by using a highly-publicized automated plagiarism detector ${ }^{16}$ to screen all internal self-study reports and summary reports. This has the foreign benefit that it forces domestic HQP to make a novel (and thus more time consuming) selfstudy at each interval and it prevents from those higher up the academic hierarchy from simply cutting and pasting from other reports.

In addition, this hierarchy of internal oversight can be used to directly slow the progress of science and engineering research in the U.S. by requiring approval from the next level up the academic hierarchy for as many functions as possible. Each function (e.g. purchasing of a chemical) can be systematized in form that has every possible permutation of variable for the function present to ensure maximum time expenditure by the American HQP. These permissions can be mandated by foreign administrative assets to be done on hard copy paper with actual physical signatures on the same piece of paper to maximize the delay for any function. Again, if any such procedures are in place administrative assets can be instructed to bump the approval process up the next level of the hierarchy with another mandated report. In the past, such small changes will in no way raise concern or suspicion and in fact may even garner administrative awards and faster promotion for the foreign asse $t^{17}$, increasing his/her worth as a foreign intelligence asset.

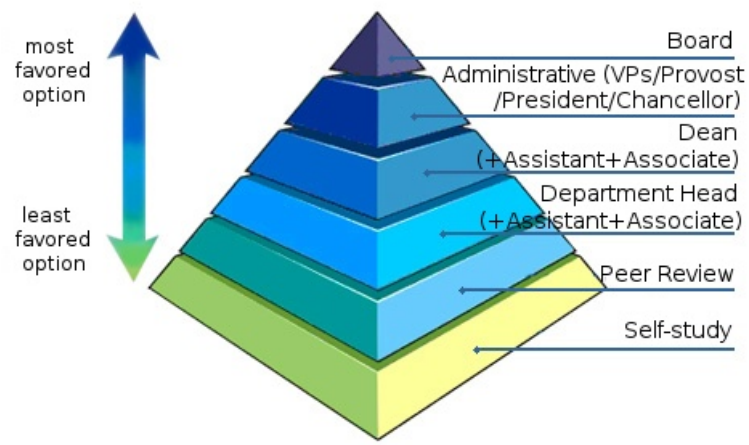

Figure 2. Hierarchy in Oversight (Internal) from Enemy Intelligence Perspective

Similar to the increasing time investments that can be demanded at the institutional level, acquiring nationallevel government administrative assets can be used to deploy a more stringent global oversight hierarchy as shown in Figure 3. The entire hierarchy in Figure 2 is summarized in the ground floor of Figure 3. National level rules and regulations can use compliance for driving administrative rules up the hierarchy in Figure 2. National-level administrative foreign assets can use the same method of using an example crisis at one institution to inflict time investments at all institutions. For example, former President of Parliamentary Commission for the Conflict of Interest and University Professor, Desa Mlikotin-Tomic, was convicted for 'trading' exam results at the Zagreb Faculty of Economics in Croatia along with 18 professors, students and mediators. ${ }^{18}$ Again all faculty in any nation including the U.S. would be expected to be "against" selling exam results. A national rule could be implemented to institute statistical analysis of all exams to look for potential cheating and be enforced by an external commission in each subdiscipline of science and engineering made up of a large number of faculty specialists as well as those in unrelated fields. Again, any time that HQP are spending on such a commission they are not working on research for the benefit of the country. 
Preprint: Joshua M. Pearce. Defense for Covert Administrative Techniques for Neutralizing American Highly Qualified Personnel. American Intelligence Journal. Vol. 33, No. 2, pp. 126-136, 2016 (in print 2017).

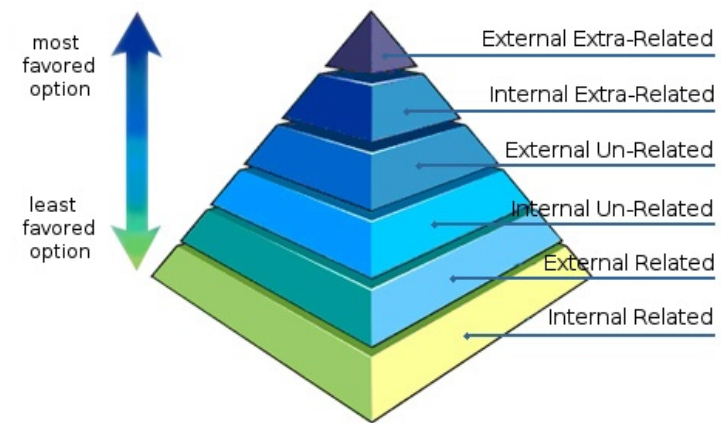

Figure 3. Hierarchy in Oversight (Global) from Enemy Intelligence Perspective

\section{Hierarchy in Scope}

Next a hierarchy in scope can be used by administrative foreign assets as a tool to increase HQP time investment in unproductive tasks. The hierarchy in scope is shown in Figure 4. For example, it may make sense for the IT department of a university to review IT-related purchases as they will be servicing them. However, this function can be extended by creating a faculty committee on IT purchases that has a representative from each organizational unit that reports to the committee whenever purchases are planned to look for potential bulk purchase discounts or other legitimate synergies. Again, the policy appears to be productive and useful, but can result in a major HQP time investment. Similarly, the breadth of stakeholders can be expanded to larger and larger communities in order to create delays. So, for example, if an HQP is attempting to build an outdoor research facility it can be proposed to the community for their opinions (who may only be indirectly affected), or the state government or even multinational organizations like the UN to look at global significance. Such scope extension can increase HQP time investments in non-productive tasks directly, but also the resultant delays can lead to frustration, which can further reduce American HQP productivity. ${ }^{19}$

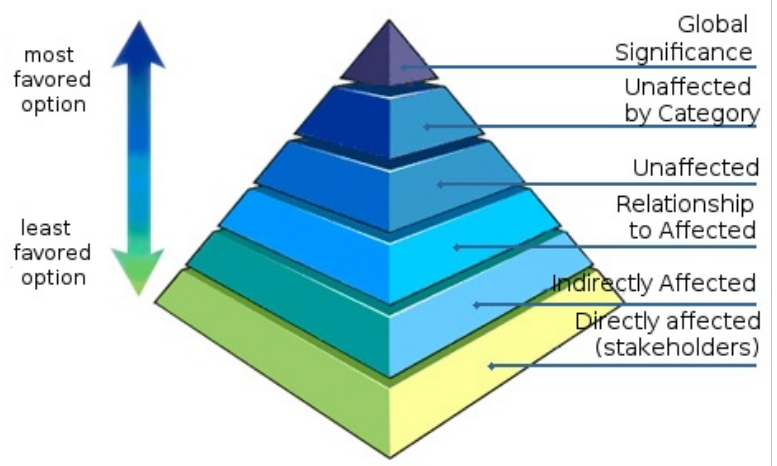

Figure 4. Hierarchy in Scope from Enemy Intelligence Perspective

\section{Hierarchy in Intrusion}

Finally, foreign intelligence organizations can use the hierarchy of intrusion, to take existing tasks and amplify the time investment necessary for the HQP. So a basic report can be mandated to online training then to onsite training. To ensure compliance foreign administrative assets can demand on site reviews that involve as wide a selection of HQP at a time - so that a single administrator can invest one day of time and use dozens of HQP-days to prepare and comply with site visits. An even superior method of HQP time destruction from foreign intelligence perspectives is to mandate off site training because then the travel time and the expense come out of HQP budgets. 
Preprint: Joshua M. Pearce. Defense for Covert Administrative Techniques for Neutralizing American Highly Qualified Personnel. American Intelligence Journal. Vol. 33, No. 2, pp. 126-136, 2016 (in print 2017).

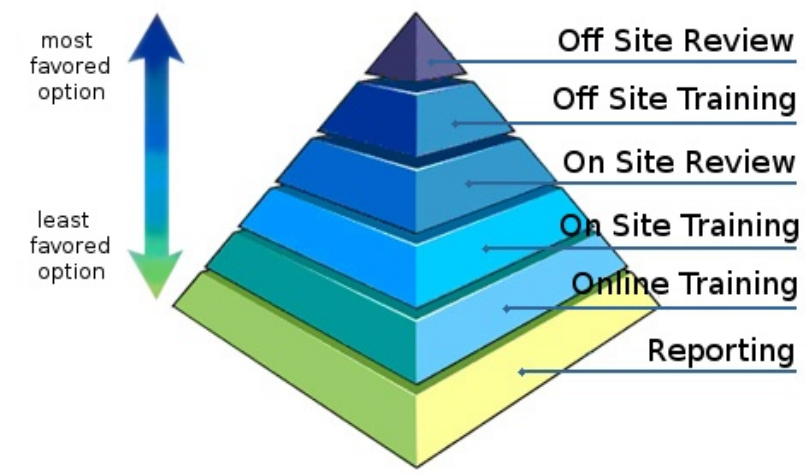

Figure 5. Hierarchy in Intrusion from Enemy Intelligence Perspective

\section{Applications}

The five hierarchical methods to transition HQP time to non-productive administrative activities can be applied in every area of academia. Here areas to be evaluated include grant writing, purchasing, reporting, outreach, budget accounting, safety, computer security, and sensitivity training. These areas are necessary for academia and academic research to function and can be expected to be supported in the general scope by academics. However, the routine procedures meant to promote a healthy academic environment will be applied by foreign administrative assets with such aggressiveness as to ensure American HQP time available for research is minimized or eliminated completely. In each case the intelligence asset can argue that excellence and best practices demand moving up the hierarchies shown in Figure 1-5.

\section{Grant Writing, Reviewing and Awarding}

Grant writing, although critical to the operation of research in most advanced nations including the U.S., is by default unproductive HQP time investments. Thus, foreign intelligence assets can be advised to do everything within their administrative scope of control to increase the amount of time American HQP must dedicate to grant writing. At the national level this can begin with the formatting and size of calls for proposals (CFPs) themselves. Best practices (for HQP time waste) would involve CFPs being written to be as long and as detailed as possible as this will increase the amount of time HQP need to invest simply in reading them. The formatting and CFP standards should be changed with every CFP cycle to ensure that HQP must read every individual CFP and discourage any copying and pasting ${ }^{20}$ from previous proposals. The CFP can be broken down into multiple parts with multiple file types that demand the use of closed source and expensive software to open and edit. The complication of the CFP will utilize time, but arbitrary proprietary formatted documents and software will further reduce research funding for research itself in the U.S. as any funds spent on arbitrary software are not being used for real research. Best practices also would involve demanding as much as possible up front in the draft cycle including: detailed budgets with each planned expenditure broken down by type with multiple quotes for anti-fraud documentation, detailed intellectual property (IP) agreements and conflict of interest forms, proposed research artifacts to be shared with the general public (e.g. Microsoft PowerPoint presentations, Final Cut Pro Video Presentations, and Adobe Photoshop Posters). To increase the HQP investment these artifacts can be further broken down into sub-groups (e.g. ages for outreach) following Figure 4.

In many countries including the U.S. grant proposals go through a system of peer review. To maximize the HQP investment, as many reviewers as possible should be requested. Normally this would be viewed as being more rigorous and again garner rewards for the foreign administrative asset requesting the change. Grant applicants should be forced to review a certain number of proposals and write summaries and recommendations with a minimum word count that they would need to do without copy/paste (again enforced by anti-plagiarism software discussed above). As many rounds of review as possible should be instituted by the foreign asset to guarantee excellence - and a committee made of HQP should write a summary of the reviews before each successive round.

Foreign administrative assets would seek to inject as many additional factors that are not based on technical excellence as possible into the review process. In addition, HQP can be required to write on and evaluate proposals on these requirements as well. Any arbitrary factor not associated with the engineering or science will effectively dilute the quality of the proposal pool if it is used for evaluations. The logical choice for the arbitrary factor will depend on 
Preprint: Joshua M. Pearce. Defense for Covert Administrative Techniques for Neutralizing American Highly Qualified Personnel. American Intelligence Journal. Vol. 33, No. 2, pp. 126-136, 2016 (in print 2017).

the social variables and culture of the region or the country. For example, requiring quotas based on gender, race, age, ethnicity, religion, skin-color or hair color or other arbitrary discriminator will ensure that some of the most qualified HQP are eliminated from consideration and funding. Similarly using discriminators such as birth location or affiliation with a political party as a litmus test for academic success by a foreign administrative asset can garner support from the ruling government party while also weakening the nation's scientific infrastructure. Defunding of the elite HQP in the U.S. using this technique again could lead to rewards for the foreign administrative asset if the appropriate social variable is selected.

Finally, even the award itself can be used to cannibalize HQP productivity time. The acceptance of the grant could be required to be made in person at a distance that involves traveling and involve detailed signing of complex forms for intellectual property, non-disclosure agreements (NDAs), etc.

\section{Purchasing}

With the advent of online shopping even scientific equipment can be purchased quickly with a credit card and shipped to most labs in the world in a matter of days. Experimental HQP are reliant on high-quality equipment to make progress in their respective fields so best practices for foreign intelligence assets using administrative techniques to neutralize HQP must slow the purchasing process as much as possible. Efforts must be made to remove the simplest form of purchasing from HQP, by for example, mandating that all equipment be passed through central purchasing rather than purchased on a credit card. Examples of scientific fraud can be used to demand that oversight. For example, a famous case in the U.S involved now felon and former professor Craig Grimes who was accused of several cases of fraud ${ }^{21}$, including defrauding the National Institutes of Health and Advanced Research Projects Agency of \$3 million in federal grant monies, much of which was misappropriated for the personal use. This mandate can be strengthened using forms that must be filled out by hand and signed justifying every purchase and tying it back to specific line items inside proposals. In addition, to ensure “appropriate use of funds” multiple vendor quotes can be required for every purchase, again actually ensuring maximum HQP time invested per purchase.

There is now considerable evidence that both free and open source software ${ }^{22}$ and free and open source hardware ${ }^{23}$ save research funding. Scaled collaboration made possible by open source design results in superior design with lower associated costs due to the continuous improvement in software code, thereby making it more robust and innovative. ${ }^{24}$ Free and open source software (FOSS) and hardware (FOSH) design can be combined with selfreplicating rapid prototyper (RepRap) 3-D printing ${ }^{25}$ for distributed digital fabrication of low-cost scientific equipment. ${ }^{26}$ The open sharing of digital design has reduced capital cost to an unprecedented 90-99\% decrease from the cost of conventional equipment. ${ }^{23}$ The lateral scaling of shared design has created substantial value resulting in hundreds and even thousands of percent return on investment for science funders. ${ }^{27}$ To stop these cost savings for science in the U.S., foreign intelligence assets must make every effort to deny the use of any form of open source software or hardware. This denial can be based most easily on security concerns, which are convoluted enough to raise questions ${ }^{28}$, regardless of the evidence that open source can be used to enhance security. ${ }^{29}$ Blanket restrictions on the use of any form of open source hardware or software can be made by any of the government agencies, funders and university administrators compromised by foreign intelligence serves to slow the rate of scientific progress in the U.S.

\section{Reporting}

After a grant is awarded for scientific research as much HQP time as possible can be relegated to reporting by foreign administrative assets in order to minimize scientific progress in the U.S. This is most easily accomplished by enhancing existing reporting requirements that are already standard among academic funding agencies using the hierarchy methods. First, for example, the repetition hierarchy can be climbed following Figure 1, by changing annual reporting requirements to monthly reports. These reports can be mandated to circulate internally first for peer review and department head or dean sign off (following Figure 2), before being sent to for external review with various committees external to the grantee's university (following Figure 3). New reports for other stakeholders could be mandated (following Figure 4), always using an incompatible format to obfuscate copy and pasting-based time-saving methods. Finally, using the strategies shown in Figure 5, progressively more intrusive reporting can be mandated along with training to do the report. Online training can involve methods to guarantee maximum time expenditure, such as long training videos with $100 \%$ pass-rate requirements on quizzes about the videos. Following this method as much reporting as possible should be mandated by foreign assets to involve site visits with multiple HQP. Ideally large numbers of such HQP from diverse disciplines would be involved, all of which would be required to travel to the site and fill out long and complex forms. 
Preprint: Joshua M. Pearce. Defense for Covert Administrative Techniques for Neutralizing American Highly Qualified Personnel. American Intelligence Journal. Vol. 33, No. 2, pp. 126-136, 2016 (in print 2017).

Outreach

Outreach to encourage STEM (Science, Technology, Engineering and Math) education is already mandatory for grants from some U.S. government organizations in order to recruit future HQP. To hobble current HQP, their role in STEM recruitment can be made a requirement for all funding and expanded substantially. As mentioned above this first can occur by expanding the scope and demand outreach materials not for one target of youth, but for every age level (Figure 4). The ideal situation from a foreign intelligence perspective would be inappropriate age groups that could not benefit the target directly from such outreach by creating more HQP. This would include both adult and geriatric science outreach, but also extremely young children. Firstly, HQP can be mandated to participate in this outreach directly (e.g. by hosting learning seminars). These seminars should be scheduled by foreign administrative assets for all regions within the target country for official reasoning about "geographic equity" and "minority group equity”, but actually for the main purpose of using additional travel time to further cut HQP productivity and travel costs to reduce funding available for research. Secondly, mandated outreach can take the form of summaries of HQP research and re-writing them at each grade level (following Figure 3). The former could be made more frequent (e.g. monthly or even weekly following Figure 1) and the latter assignment can be checked using automated tools already available in proprietary text editing software such as Word Perfect, which again would lead to further draw down on research moneys for unnecessary proprietary software.

\section{Budget Accounting}

Perhaps the most natural method to accelerate HQP time expenditures while seeming to adopt best administrative practices is in the use of aggressive budget accounting. With the use of the detailed plan of expenditures developed as part of the grant writing process including full competing quotes for each purchase, it is possible to do line item audits of all expenditures. Administrators will need to be hired to review and audit these expenditures, which will further drive up overhead costs and reduce spending for research in the U.S. There are numerous international examples to draw from where faculty have misused research funds, which can be used as justification of the need for this level of due diligence. This due diligence can also be used for detailed conflicts of interest audits, where HQP would be asked to report all personal investments and all investments of their relatives. The scope of relatives can be expanded following Figure 3 (e.g. to spouses of blood relatives and their relatives). For HQP with multiple projects it can be required that they produce a time log for value accounting for each project. This is already practiced in some industries, but again using the five hierarchies can be expanded into a significant time commitment. Finally, HQP can be responsible for developing detailed reports of any in-kind contribution they claim toward a project. To make these processes as time consuming as possible, foreign administrative assets can require HQP to account for their activities every 15 minutes throughout their working time and assign that time to a specific budget for a specific contract. This could be accomplished, for example, with software that beeps every 15 minutes and freezes the computer screen of the HQP before they comply with filling out a multiple part form. This strategy has two core benefits. First, it reduces the actual research time of the HQP to fill out the form. Second, and more importantly, interruptions decrease performance and efficiency, but add to stress and mental loads for the HQP. ${ }^{30}$ Each interruption reduces the ability of the HQP to perform challenging mental tasks and deep thinking that lead to scientific and technical advancement. Foreign administrative assets can ensure that any HQP that complains about the accounting oversight can be immediately publicly audited for their entire academic career to provide a disincentive for any movement against greater time expenditures.

\section{Safety}

"Safety first" is a common slogan used in both industry and academia and no one wants to work in an unsafe environment. Thus a call to create an enhanced "safety culture" of "safety climate" 31 should be met with a minimum of resistance from HQP faculty at America's universities. Following Figure 1, routine safety audits can be mandated and increased in frequency. Such safety tours can be done in large groups (peer review via Figure 2) of all effected HQP (and even better from a foreign intelligence perspective — by unaffected HQP following Figure 3). In addition, to onsite review, HQP can be mandated to attend a number of offsite "best practices" safety tours in industry, government labs or other academic institutions (Figure 5). Again, travel time should be maximized to minimize available research time and research expenditures on travel. In addition, mandatory safety training can take the form of online training. This training can be arranged to maximize HQP investment by having password protected login under the HQP name, linear lectures with video that cannot be paused (and restart form the beginning if stopped for 
Preprint: Joshua M. Pearce. Defense for Covert Administrative Techniques for Neutralizing American Highly Qualified Personnel. American Intelligence Journal. Vol. 33, No. 2, pp. 126-136, 2016 (in print 2017).

any reason) and online detailed quizzes to ensure that HQP are concentrating on the minutia of the videos. As one can never be too safe, this application can be a good candidate for a form of continuous improvement, which will use a cyclical large amounts of HQP time on non-productive tasks.

\section{Computer Security}

There is a consistent series of news articles discussing the risk of cyber-attacks and the needs for computer security. ${ }^{32}$ There is a well-established national hacking initiatives ${ }^{33}$ used to steal research secrets. Thus, it is a reasonable administrative request to ensure computer security. One of the easiest methods of improving computer security is to ensure that un-authorized people do not gain access to the network when HQP leave their desks. This can be accomplished with auto logoffs, which log out of a computer after a given amount of time. For optimal security the time before auto logoff should be minimized (e.g. 10 minutes or less) on all computers including HQP desk computers and computers that run scientific equipment. This follows the goal of maximizing repetition of this autologging off found in Figure 1. The password rules should also be as convoluted as possible, use multi-authentication and change frequently in order to use more HQP time. Fortunately, high-security password recommendations follow this protocol. As noted above, constantly needing to relog into a machine causes interruptions, which decrease performance and efficiency, but also to stress and mental loads for the HQP. In addition, HQP can be required to register their proprietary software personally, and update it following an advanced hierarchy or repetition. Computer security can also be used as means of justifying repeating backup requirements during working hours by the HQP themselves. This will all reduce active HQP research time and thus research quality and quantity of output, while at the same time improving the performance of the administrative metrics of research.

\section{Sensitivity Training}

HQP research time can be effectively reduced by mandating continuous education in areas that do not add to their technical competence. These areas of investigation that are most appropriate for using in this mechanism are dependent on the culture of the target. For example, sensitivity training can be used based on race, sex, age, or class. Sensitivity training topics should be chosen that the majority of HQP agree with on principle (e.g. faculty should not be discriminated against by age). The training can be coupled to audits of potential discrimination (e.g. age, sex, religion-based annual surveys to ensure that there is not a non-representative population of HQP). This information can be used to shut out the best HQP from positions, weakening the nation's talent pool (e.g. by setting up race quotas). Then following Figure 1, both routine sensitivity audits and training can be mandated and increased in frequency. The audits will take time for HQP to complete and should be made as complicated and detailed as possible. Then the training can be done in large groups (peer review via Figure 2) of all effected HQP (and even better by unaffected HQP following Figure 3). Committees can be arranged with mandatory representatives from each subgroup, again using valuable HQP time. Finally, using the strategies shown in Figure 5, progressively more intrusive reporting can be mandated along with training to do the sensitivities reports themselves. Online training should involve methods to guarantee maximum time expenditure, such as long training videos with $100 \%$ to pass-rate quizzes about the videos. As much reporting should, however, involve site visits with multiple HQP, ideally large numbers of such from diverse disciplines all which must travel to the site and fill out long and complex forms to ensure they are not being discriminatory.

\section{Beyond Time}

New policies created by foreign administrative intelligence assets that directly use HQP time in the U.S. are the most valuable towards reaching their goal of 12 additional hours of unproductive time investment per week. However, foreign intelligence services could use other mechanisms to drive the effective overhead on research funding. If a specific finite amount of resources is dedicated to research and development by Americans, foreign intelligence would attempt to force as much of those resources as possible be diverted to non-research-related overhead. There is already a mechanism using overhead at most institutions in the U.S. that facilitate the transfer of research funds from productive research to administrative salaries and in some cases building depreciation. ${ }^{34}$ Interestingly, in the latest Grant Proposal Guideline for the National Science Foundation the use of lower overhead rates will now be considered a violation of their cost sharing policy, thereby decreasing money used for innovation directly. ${ }^{35}$ Following the hierarchy systems and target applications above can all contribute to this creation of overhead. For example, staff for research services will be needed to help assemble complicated budgets and to ensure appropriate research accounting and oversight rules are being followed. New types of administrators will be needed, 
Preprint: Joshua M. Pearce. Defense for Covert Administrative Techniques for Neutralizing American Highly Qualified Personnel. American Intelligence Journal. Vol. 33, No. 2, pp. 126-136, 2016 (in print 2017).

all pulling salaries out of expanded overhead rates, to follow the new national level rules and to make rules and ensure compliance locally. In general, these administrators will be less educated than the HQP, which are the targets. Thus, they are paid less, so to make effective use of administrative overhead reductions many more administrators are needed than HQP targets.

The breadth of the scientific and engineering establishment in the U.S. is too large to attack using the historical techniques such as assassination. For example, in 1943, British bombers attacking Germany rocket testing facilities including the V-2, decided the primary targets should be the homes of the scientists and engineers associated with the program and key HQP were killed during the raids. ${ }^{36}$ Similarly, in 1944 an officer from the Office of Strategic Services (OSS) attended a lecture by German physicist Werner Heisenberg, with a kill order if he was convinced Germany was capable of an atomic bomb. ${ }^{37}$ Fortunately for Heisenberg, the would-be assassin was convinced that no such bomb was eminent. These examples, were during a time of official war, but scientists have also been targeted outside of war. In 1980, Yahya al-Meshad, an Egyptian-born metallurgist and a member of the Iraqi Atomic Energy Commission, was murdered in his Paris, when arranging a shipment of nuclear fuels from France to Iraq. This attack and others to disrupt the nuclear collaboration between France and Iraq as well as earlier attacks on German scientists collaborating with Egypt on rockets, have been considered to be the work of Israel's Intelligence Service. ${ }^{38}$ What they all share in common is a fairly small scale focused attack on a few scientists. The new formalized methods presented here can be applied outside of an official declaration of war and can have broad wide-scale impacts on the economy of the U.S. Overall, a critical review of these techniques presented here provide results that appear to be an appropriate method for eliminating the effectiveness of HQP in the U.S. by foreign intelligence assets. In addition, they are less likely to be detected because the techniques fit well into conventional administrative practice and would be seen as a gradual administrative overreach rather than a widespread assassination plot of thousands of scientists, which would be more likely to resort in some form of retaliation or war. It should be pointed out that the applications of such techniques is not new. The CIA's precursor, the Office of Strategic Services (OSS), made similar recommendations in the form of sabotage for citizens of a foreign country that do not agree with their government. ${ }^{39}$ Using the non-violent methods outlined here, a foreign intelligence service needs to infiltrate a relatively small number of administrative ranks for the techniques to function. The techniques if applied in aggregate can easily shift the needed $20 \%$ percent of HQP time to administration, which would be expected to cripple the American innovation cycle.

\section{Defense Against Administrative Techniques to Neutralize American HQP}

Future work is needed to quantify the effectiveness of these techniques, how widespread they already are and counter-intelligence methods needed to detect if administration have been compromised in government, business, organization or university. However, it is hoped simply outlining these methods can provide some defense and some basic recommendations can be made here to help protect the U.S. from these forms of administrative attacks on American HQP.

First, American administrators at every level should work to maximize the amount of time HQP can spend on research by minimizing their administrative functions. Administrators can do a thought experiment on every rule asking how much HQP time per year the rule will invoke and can prioritize means to minimize this investment. As the values in the introduction made apparent, reducing HQP administrative time to zero, may be able to double national research output. To do this, administrators should look closely at their organization's rules to see if they can push down the hierarchies in Figure 1-5. For example, if a faculty self-study review is currently warranted annually can the time between reviews be expanded to 2 years or perhaps at each promotion (e.g. 5-7 years)?

Second, administrators should attempt to isolate legitimate issues rather than have blanket policies that waste HQP time. For a security example, rather than auto log off the every faculty computer ever 10 minutes across the university, university faculty that work on national security sensitive research should have their facilities physically locked down to prevent unauthorized access to their computers.

Third, to begin to search out compromised administrators, leaders in each administrative unit can evaluate if administrative burdens have been increasing because of rule changes within their own organizations. In any administrative unit where such HQP time expenditures have been increasing, the administrators in charge of the rule change should be vetted carefully to ensure they have not been compromised by foreign intelligence services and means should be identified to reverse these HQP time expenditures.

Finally, national government organizations in particular must be vigilant to ensure their organizations are providing clear and terse guidelines to minimize administrative overreach in smaller institutions (e.g. universities) that make up the majority of HQP time expenditures. 
Preprint: Joshua M. Pearce. Defense for Covert Administrative Techniques for Neutralizing American Highly Qualified Personnel. American Intelligence Journal. Vol. 33, No. 2, pp. 126-136, 2016 (in print 2017).

\section{Conclusions}

This study analyzed a new approach of covert foreign infiltration to enable administrative techniques to neutralize HQP in U.S. without assassination or recruiting HQP directly. The five hierarchical strategies to increase administrative time expenditures for target HQP were applied to the areas of grant writing, purchasing, reporting, outreach, budget accounting, safety, computer security, and sensitivity training. Techniques were shown to increase the working time of HQP on non-productive labor at the expense of innovation over broad swaths of technological space, which would be expected to weaken both national security and the overall economy. By describing the techniques foreign intelligence services will be less likely to successfully implement them. In addition, several policy recommendations were made to conserve HQP innovation time. 


\section{Notes}

1 See for example: Doel, R.E. and Needell, A.A., 1997. Science, scientists, and the CIA: Balancing international ideals, national needs, and professional opportunities. Intelligence and National Security, 12(1), pp.59-81. Orlov, Vladimir A., and Alexander Vinnikov. "The great guessing game: Russia and the Iranian nuclear issue." Washington Quarterly 28, no. 2 (2005): 49-66. Richelson, Jeffrey T. The wizards of Langley: inside the CIA's Directorate of Science and Technology. Basic Books, 2002. Richelson, Jeffrey. Spying on the bomb: American nuclear intelligence from Nazi Germany to Iran and North Korea. WW Norton \& Company, 2007.

${ }^{2}$ See: Stokes, Donald E. Pasteur's quadrant: Basic science and technological innovation. Brookings Institution Press, 1997. For a more up-to-date summary see: Feldman, Maryann P., Albert N. Link, and Donald Siegel. The economics of science and technology: an overview of initiatives to foster innovation, entrepreneurship, and economic growth. Springer Science \& Business Media, 2012.

${ }^{3}$ Schofer, Evan, Francisco O. Ramirez, and John W. Meyer. "The effects of science on national economic development, 1970 to 1990." American Sociological Review (2000): 866-887.

${ }^{4}$ Many studies concur, see for example: Schultz, Theodore W. "Investment in human capital." The American economic review 51, no. 1 (1961): 1-17. Schultz, Theodore William. The economic value of education. Vol. 63. New York: Columbia University Press, 1963. Jones, Graham. "The role of science and technology in developing countries." The role of science and technology in developing countries (1971). Psacharopoulos, G., 1981. Returns to education: An updated international comparison. Comparative education, 17(3), pp.321-341. Psacharopoulos, George. "Returns to education: a further international update and implications." Journal of human resources (1985): 583-604. Psacharopoulos, G. "Returns to investment in education: A global update." World development 22, no. 9 (1994): 1325-1343. Blundell, R., Dearden, L., Meghir, C. and Sianesi, B., 1999. Human capital investment: the returns from education and training to the individual, the firm and the economy. Fiscal studies, 20(1), pp.1-23.

${ }^{5}$ These studies include: Matthews, R.C.O., 1973. The Contribution of Science and Technology to Economic Development (pp. 1-38). Palgrave Macmillan UK. Liyan, Yang, and Pan Huifeng. "Human Capital, Basic Scientific Research and Economic Growth." Economic Research Journal 4 (2003): 007. Salter, Ammon J., and Ben R. Martin. "The economic benefits of publicly funded basic research: a critical review." Research policy 30, no. 3 (2001): 509-532.

${ }^{6}$ Wechsler, "The Measurement and Appraisal of Adult Intelligence" (1958). See http://www.assessmentpsychology.com/iq.htm for and accessible version.

${ }^{7}$ See: Psacharapoulos refs. 11-13.

${ }^{8}$ Sternberg, Robert J., and Linda A. O’Hara. "13 Creativity and Intelligence." Handbook of creativity (1999): 251.

${ }^{9}$ U.S. Bureau of Labor Statistics, U.S. Department of Labor, Occupational Outlook Handbook, 2016-17 Edition, Postsecondary Teachers, on the Internet at http://www.bls.gov/ooh/education-training-and-library/postsecondaryteachers.htm (visited March 14, 2016).

${ }^{10}$ Weissmann, J., 2013. How many Ph. D.'s actually get to become college professors. The Atlantic, 23.

${ }^{11}$ Examples of assassination include: Tobey, W., 2012. Nuclear scientists as assassination targets. Bulletin of the Atomic Scientists, 68(1), pp.61-69. Meisels, Tamar. "Assassination: Targeting nuclear scientists." Law and Philosophy 33, no. 2 (2014): 207-234. Richelson, Jeffrey T. "When kindness fails: assassination as a national security option." International Journal of Intelligence and Counterintelligence 15, no. 2 (2002): 243-274.

${ }^{12}$ Infiltration examples include: Johnson, Loch K. "The CIA and the Media." Intelligence and National Security 1, no. 2 (1986): 143-169. Coll, Steve. Ghost Wars: The Secret History of the CIA, Afghanistan, and bin Laden, from the Soviet Invas ion to September 10, 2001. Penguin, 2004. CNN. "Cold War Freedom Fighter's Manual". CNN. Archived 2006.

https://web.archive.org/web/20060210134317/http://www.cnn.com/SPECIALS/cold.war/episodes/18/documents /cia.ops/

13 See Meisels, Tobey and Richelson (footnote 11) for some of this discussion.

${ }^{14}$ Bio-based warfare examples: Langmuir, Alexander D., and Justin M. Andrews. "Biological Warfare Defense* The Epidemic Intelligence Service of the Communicable Disease Center." American Journal of Public Health 


\section{Notes}

and the Nations Health 42, no. 3 (1952): 235-238. Christopher, LTC George W., LTC Theodore J. Cieslak, Julie A. Pavlin, and Edward M. Eitzen. "Biological warfare: a historical perspective." Jama 278, no. 5 (1997): 412417. Kortepeter, Mark G., and Gerald W. Parker. "Potential biological weapons threats." Emerging infectious diseases 5, no. 4 (1999): 523.

${ }^{15}$ See for example discussions of academic workload in: Flaherty, Colleen. "So much to do, so little time." Inside Higher Ed (2014). Available: https://www.insidehighered.com/news/2014/04/09/research-shows-professorswork-long-hours-and-spend-much-day-meetings

Cataldi, Emily Forrest, Mansour Fahimi, Ellen M. Bradburn, and Linda Zimbler. "2004 National Study of Postsecondary Faculty (NSOPF: 04) Report on Faculty and Instructional Staff in Fall 2003. ED TAB. NCES 2005-172." US Department of Education (2005).

${ }^{16}$ Such services include: TurnItIn, iThenticate, Viper, WriteCheck, Plagiarism Checker, etc.

${ }^{17}$ Gibbs, Michael, and Wallace Hendricks. "Do formal salary systems really matter?." Industrial \& Labor Relations Review 58, no. 1 (2004): 71-93.

18 Dalje. 2010. Corrupt professor sentenced to 14 months. http://arhiva.dalje.com/en-croatia/photos corruptprofessor-sentenced-to-14-months/292475

${ }^{19}$ Karasek, Robert, and Töres Theorell. Healthy work: stress, productivity, and the reconstruction of working life. Basic books, 1992.

${ }^{20}$ Again plagiarism software can be used and highly publicized.

${ }^{21}$ Reich, Eugenie Samuel. "Duplicate-grant case puts funders under pressure." Nature 482, no. 7384 (2012): 146. Reich, "Duplicate-grant case puts funders under pressure.(2012) and http://abc27.com/2012/11/30/former-psuprofessor-sentenced-to-prison-for-research-fraud/

${ }^{22}$ FOSS is discussed in detail in the literature including: Lakhani, Karim R., and Eric Von Hippel. "How open source software works:“free” user-to-user assistance." Research policy 32, no. 6 (2003): 923-943. Kogut, Bruce, and Anca Metiu. "Open-source software development and distributed innovation." Oxford Review of Economic Policy 17, no. 2 (2001): 248-264. Ven, Kris, Jan Verelst, and Herwig Mannaert. "Should you adopt open source software?." Software, IEEE 25, no. 3 (2008): 54-59.

${ }^{23}$ FOSH is less well developed but there is some evidence including: Pearce, Joshua M. "Building research equipment with free, open-source hardware." Science 337, no. 6100 (2012): 1303-1304. Pearce, Joshua M. Open-source lab: how to build your own hardware and reduce research costs. Elsevier, 2013.

${ }^{24}$ Raymond, Eric. "The cathedral and the bazaar." Knowledge, Technology \& Policy 12, no. 3 (1999): 23-49. ${ }^{25}$ Jones, Rhys, Patrick Haufe, Edward Sells, Pejman Iravani, Vik Olliver, Chris Palmer, and Adrian Bowyer. "RepRap-the replicating rapid prototyper."Robotica 29, no. 01 (2011): 177-191.

${ }^{26}$ See examples in biotech: Wittbrodt, Jonas N., Urban Liebel, and Jochen Gehrig. "Generation of orientation tools for automated zebrafish screening assays using desktop 3D printing." BMC biotechnology 14, no. 1 (2014): 1. Gross, Bethany C., Jayda L. Erkal, Sarah Y. Lockwood, Chengpeng Chen, and Dana M. Spence. "Evaluation of 3D printing and its potential impact on biotechnology and the chemical sciences." Analytical chemistry 86, no. 7 (2014): 3240-3253. Lücking, Tim H., Franziska Sambale, Sascha Beutel, and Thomas Scheper. "3D-printed individual labware in biosciences by rapid prototyping: A proof of principle." Engineering in Life Sciences 15, no. 1 (2015): 51-56.

There are also physics/optics examples: Zhang, C., N.C. Anzalone, R. P. Faria, and J. M. Pearce. "Open-source 3D-printable optics equipment." PloS one 8, no. 3 (2013): e59840. Sharkey, James P., Darryl CW Foo, Alexandre Kabla, Jeremy J. Baumberg, and Richard W. Bowman. "A one-piece 3D printed microscope and flexure translation stage." arXiv preprint arXiv:1509.05394 (2015). Wijnen, B., Petersen, E.E., Hunt, E.J. and Pearce, J.M., 2016. Free and open-source automated 3-D microscope. Journal of Microscopy, 264(2), pp.238-246. Syringe pumps for biology, chemistry or engineering applications: Wijnen, Bas, Emily J. Hunt, Gerald C. Anzalone, and Joshua M. Pearce. "Open-source syringe pump library." PloS one 9, no. 9 (2014): e107216. Finally, medical examples include: Herrmann, Karl-Heinz, Clemens Gärtner, Daniel Güllmar, Martin Krämer, and Jürgen R. Reichenbach. "3D printing of MRI compatible components: Why every MRI research group should have a low-budget 3D printer." Medical engineering \& physics 36, no. 10 (2014): 1373-1380.

${ }^{27}$ For determining value: Pearce, Joshua M. "Quantifying the value of open source hardware development." Modern Economy 6, no. 1 (2015): 1-11. And the ROI: Pearce, J. M. "Return on investment for open source 


\section{Notes}

scientific hardware development." Science and Public Policy (2015) 43 (2): 192-195.

${ }^{28}$ Payne, Christian. "On the security of open source software." Information Systems Journal 12(1) (2002): 61-78. For a more recent summary: Lawton, George. "Open source security: opportunity or oxymoron?." Computer 35, no. 3 (2002): 18-21.

${ }^{29}$ Hoepman, Jaap-Henk, and Bart Jacobs. "Increased security through open source." Communications of the ACM 50, no. 1 (2007): 79-83. Cowan, Crispin. "Software security for open-source systems." IEEE Security \& Privacy 1 (2003): 38-45.

${ }^{30}$ There is well established evidence of this- see: Jackson, Thomas, Ray Dawson, and Darren Wilson. "The cost of email interruption." Journal of Systems and Information Technology 5, no. 1 (2001): 81-92. Spira, J.B. and Feintuch, J.B. The cost of not paying attention: How interruptions impact knowledge worker productivity. New York, NY: Basex, 2005. Karr-Wisniewski, Pamela, and Ying Lu. "When more is too much: Operationalizing technology overload and exploring its impact on knowledge worker productivity." Computers in Human Behavior 26, no. 5 (2010): 1061-1072. Tarafdar, Monideepa, Qiang Tu, and T. S. Ragu-Nathan. "Impact of technostress on end-user satisfaction and performance." Journal of Management Information Systems 27, no. 3 (2010): 303-334.

${ }^{31}$ Coyle, Ian R., Stuart David Sleeman, and Neil Adams. "Safety climate." Journal of Safety Research 26, no. 4 (1996): 247-254.

${ }^{32}$ Examples include: Clark, David D., and David R. Wilson. "A comparison of commercial and military computer security policies." In Security and Privacy, 1987 IEEE Symposium on, pp. 184-184. IEEE, 1987. Ericsson, Göran N. "Cyber security and power system communication—essential parts of a smart grid infrastructure." Power Delivery, IEEE Transactions on 25, no. 3 (2010): 1501-1507. Bishop, Matt. "What is computer security?." Security \& Privacy, IEEE 1, no. 1 (2003): 67-69. Amoroso, Edward G. Fundamentals of computer security technology. Prentice-Hall, Inc., 1994. Richardson, Robert, and C. S. I. Director. "CSI computer crime and security survey." Computer Security Institute 1 (2008): 1-30.

${ }^{33}$ National initiatives: Jinn, Guo-Woei. China's development of asymmetric warfare and the security of Taiwan, Republic of China. Naval Postgraduate School Monterey, CA, 2004. Cendrowski, S. Evidence of China's statesupported hacking grows. Fortune. Sept. 24, 2015. Ward, M. Does China’s government hack US companies to steal secrets? BBC. Sept. 2015. Available: http://www.bbc.com/news/technology-34324252

${ }^{34}$ Ginsberg, Benjamin. The fall of the faculty. Oxford University Press, 2011.

${ }^{35}$ How the NSF will handle "indirect costs" (also known as facilities and administrative costs (F\&A) for colleges and universities), has been updated starting Jan. 30, 2017 to clarify that the use of an indirect cost rate lower than the organization's approved negotiated indirect cost rate is considered a violation of NSF's cost sharing policy. This effectively means a federal organization just changed their own rule to decrease the amount of money they invest directly on research. Most egregiously, many institutions have an 'on campus' and 'off campus' negotiated overhead rates with the latter being lower. Some universities are interpreting this new rule to mean that faculty are no longer able to voluntarily choose to use the off-campus rate for the major grants such as the CAREER Program as was common practice in the past. The guide is available here https://www.nsf.gov/pubs/policydocs/pappg17 1/ and the changes are summarized here: https://www.nsf.gov/pubs/policydocs/pappg17 1/sigchanges.jsp

${ }^{36}$ Historical examples: Hinsley, F. H., E. E. Thomas, C. F. G. Ransom, and R. C. Knight, British Intelligence in the Second World War, Volume 2, Part I (New York: Cambridge University Press, 1984), p. 382.

Babington-Smith, Air-Spy (1957), p. 212. Babington-Smith, C.Air-Spy: The Story of Photo Intelligence in World War II (New York: Harper, 1957). Jones, R. V. The Wizard War: British Scientific Intelligence 1939-1945 (New York: Coward, McCann \& Geohagen, 1978).

${ }^{37}$ Dawidoff, N. The Catcher Was a Spy: The Mysterious Life of Moe Berg (New York: Pantheon, 1994), pp. 199207.

${ }^{38}$ Black, B. and Morris, B. Israel's Secret Wars: A History of Israel's Intelligence Services (New York: Grove Weidenfeld, 1991).

${ }^{39}$ CIA. 2012. Timeless Tips for 'Simple Sabotage'. Available https://www.cia.gov/news-information/featuredstory-archive/2012-featured-story-archive/simple-sabotage.html Original manual: https://www.cia.gov/news- 


\section{Notes}

information/featured-story-archive/2012-featured-story-archive/CleanedUOSSSimpleSabotage sm.pdf

\section{Author Bio:}

Joshua M. Pearce received his Ph.D. from the Pennsylvania State University. He is currently is Associate Professor crossappointed in the Department of Materials Science \& Engineering and in the Department of Electrical \& Computer Engineering at the Michigan Technological University. His research concentrating on improving technical and organizational efficiency has been funded by the Department of Defense, Department of Energy, and the National Science Foundation, utilities and numerous manufacturers, systems designers and investors. He recently received the Silver Quill Award from Brigadier General Anthony Funkhouser, commander of the Northwestern Division, U.S. Army Corps of Engineers for his writing covering the protection of U.S. manufacturing interests. 